pestilence and the ravages of any number of diseases that modern medicine, by controlling nature, can prevent or treat. In prescientific agrarian society, life was a perpetual struggle in which the scarcity of resources led to a hierarchical, authoritarian form of organization in which most people suffered or prospered according to prescribed rank.

Indeed it is precisely because humanity has learnt to control some aspects of nature that civilization has advanced. Economic growth is the child of science and technology. To cry "Enough is enough", as Speth would have us do, would be to abandon any hope of substantially diminishing poverty, hunger and disease in the world. Without the contribution of science and technology, the task of preserving and enhancing the quality of life on our planet would be impossible. Speth raises serious issues, but they deserve a more balanced treatment than the prescriptions in his book.

Dick Taverne is chairman of the charity Sense

About Science, 60 Cambridge Street,

London SW1V 4QQ, UK.

\section{Crossing the boundary}

\section{Biological Physics: Energy, Information, Life \\ by Philip Nelson \\ W. H. Freeman: 2004.600 pp. $£ 34.99, \$ 106.50$ \\ Christopher M. Dobson}

"Physics is what physicists do." This definition, which is current in at least some physics departments, is not intended (we trust) simply to confuse the rest of the scientific community. Rather, it suggests that the discipline of physics, more conventionally defined (in the Shorter Oxford English Dictionary) as the branch of science "that deals with the nature and properties of matter and energy", can be brought to bear on a wide range of problems across the broad spectrum of human knowledge.

Indeed, 100 years ago, physicists brought about a revolution in chemistry, when the discovery of the electron led to an understanding of the nature of atoms and of molecular structure and bonding. And 50 years ago, physicists ushered in a revolution in biology, with dramatic demonstrations that $\mathrm{X}$-ray diffraction could reveal the structures of DNA and proteins. Nevertheless, relatively few physicists have been "doing biology", and many of these migrated from mainstream physics departments to set up enterprises such as the Laboratory of Molecular Biology in Cambridge, UK, or the Institute of Protein Research in Puschino, Russia.

But times are changing. Physicists in physics departments are now increasingly

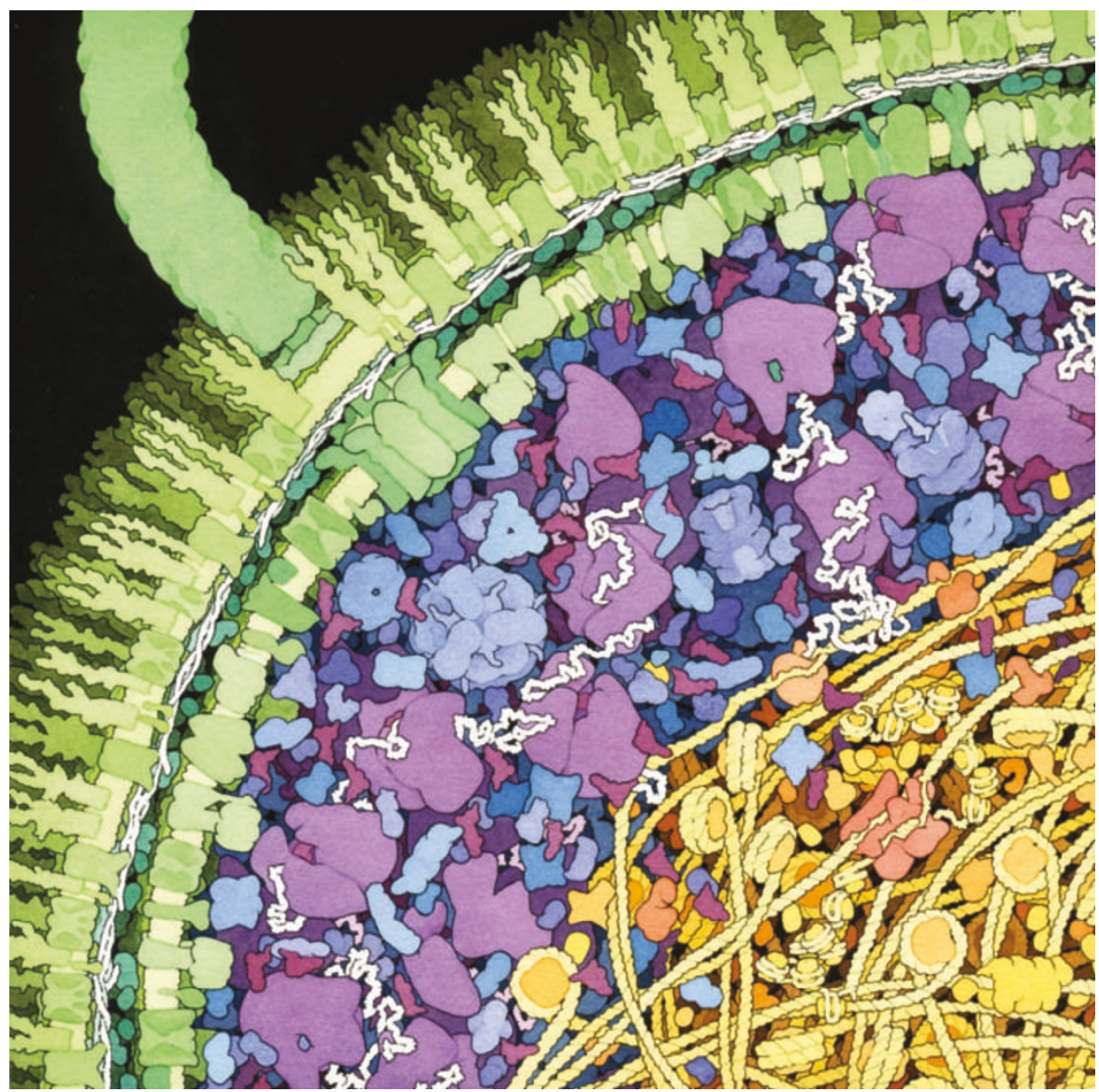

Living colour: David Goodsell's 'crowded cell' image of the bacterium Escherichia coli.

looking around for grand challenges to rival those that led to major advances in our understanding of many aspects of the physical world, from the fundamental particles of matter to the origins of the Universe. And biology, the study of the nature of life itself, is not short of such challenging problems. Some of these are likely to succumb to bigger and better physical techniques; others might well be revolutionized by the reductionist approach so favoured by physicists to identify and tease out fundamental principles from the vast arrays of data that such techniques can generate.

If such grand challenges are to be tackled successfully, however, it is crucial that physicists collaborate with biologists, and with those in other disciplines, including chemistry, mathematics and medicine. For such collaborations to work, there has to be a common language and an appreciation of the strengths and weaknesses of each other's abilities.

Philip Nelson's excellent text, Biological Physics, provides material for the types of course we should now be offering to all our students. Nelson says that his book is for "life science students who are willing to use calculus" and for "physical science and engineering students who are willing to think about cells". And indeed, his book should educate and intrigue both groups. Particularly impressive is the subtle way that topics that often cause the eyes of even the most diligent student to glaze over are made to seem not just interesting to read about but compelling to learn. Statistical mechanics and thermodynamics are obvious examples, and key concepts such as the Boltzmann distribution and free energy are introduced to explain such questions as why "cells do not work best at the coldest temperatures", despite the fact that life is about generating highly ordered structures. Moreover, although much emphasis is placed on understanding ideas, the text does not allow anyone to forget that some real equations need to be mastered if such an understanding is to be satisfying and widely applicable.

Another good aspect of this book is that it is right up to date in the topics and examples that it covers. Many relatively recent ideas, such as the use of free-energy surfaces for understanding protein folding and of optical tweezers for probing muscle action, are covered in depth, with at least some references to the original literature. There are frequent comments about the way that modern ideas and techniques have emerged. As Nelson cleverly shows, many of the most important scientific breakthroughs have come about unexpectedly through just the type of interdisciplinary studies that this book promotes.

For example, it was the renowned physicist Robert Hooke who realized in the midseventeenth century, after peering down a microscope that he himself had constructed, 
that living systems are made up of discrete compartments that he called cells. And looking down another microscope in the early nineteenth century, botanist Robert Brown saw pollen grains that were "evidently in motion". When further experiments showed that the movement was not the result of some sort of life force, he realized that he was observing a general property of finely divided matter. His observations of 'brownian motion' - the result of collisions between dynamic particles - were later to be interpreted by Einstein in his doctoral thesis, work that laid the foundations for quantum theory. It is compelling stuff.

So is this book a perfect work of science? Perhaps almost so, although at first sight a biologist might not think so. Nelson's book makes frequent use of drawings of biological structures, notably many by David Goodsell, including his famous image of a 'crowded cell'. By contrast, most modern biology texts, even relatively inexpensive ones, have been transformed by the power of modern microscopy and sophisticated moleculargraphics programs.
Still, the handful of colour pictures in this book demonstrate that one of the many attractions of living systems is frequently their great beauty. And simple observations of biological systems have long influenced the progress of physics: after all, the moving object said to have triggered Newton's understanding of gravity was undoubtedly of biological origin.

Christopher M. Dobson is at the Cavendish Laboratory and the Department of Chemistry, University of Cambridge, Lensfield Road, Cambridge CB2 1EW, UK.
Theatre

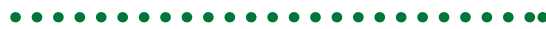
A stage of evolution The Darwin Variations

by Jean-François Peyret \& Alain Prochiantz Performed in French at the Théâtre National de Chaillot, Paris, until 18 December 2004.

\section{Laura Spinney}

Darwin's theory of natural selection has been handed down to us as the broad vision of a brilliant man, meticulously researched, comprehensive and self-assured. We hear less about his doubts, his procrastination and anguished discussions with contemporaries. Nor is it well-known that, in confronting the implications of his theory, he made himself ill. "I'm sick to the stomach," he confesses at times throughout The Darwin Variations.

This play sets the science in the context of the man and his time. The process of publication tends to strip away all the emotion, poetry and music of a discovery. So Alain Prochiantz, a developmental neurobiologist at the Ecole Normale Supérieure, Paris, and theatre director Jean-François Peyret have set out to recreate it. They have given Darwin the poetic licence that Ovid took for granted when he wrote his poem Metamorphoses. Like Ovid, the actors in The Darwin Variations are free to imagine the future transformation of humanity - even a humanity that takes charge of its own evolution. Their musings intertwine with Darwin's in a dialogue that takes in old and new ideas, about where to draw the line between man and animal, and about consciousness, genetic engineering and interfaces between brain and machine. Over all of this hangs the threat of the inevitable conclusion: that there is no grand design, no notion of perfection to which evolution is propelling us.

This conclusion is embodied by the action on stage. This is theatre of the absurd, where nothing happens for a reason. Actors move about in a disconnected way, apparently oblivious to an off-stage dialogue. The speakers are invisible, but their voices seem to press in on the set, clamouring to be let in. Every so often they succeed, and the actors respond.

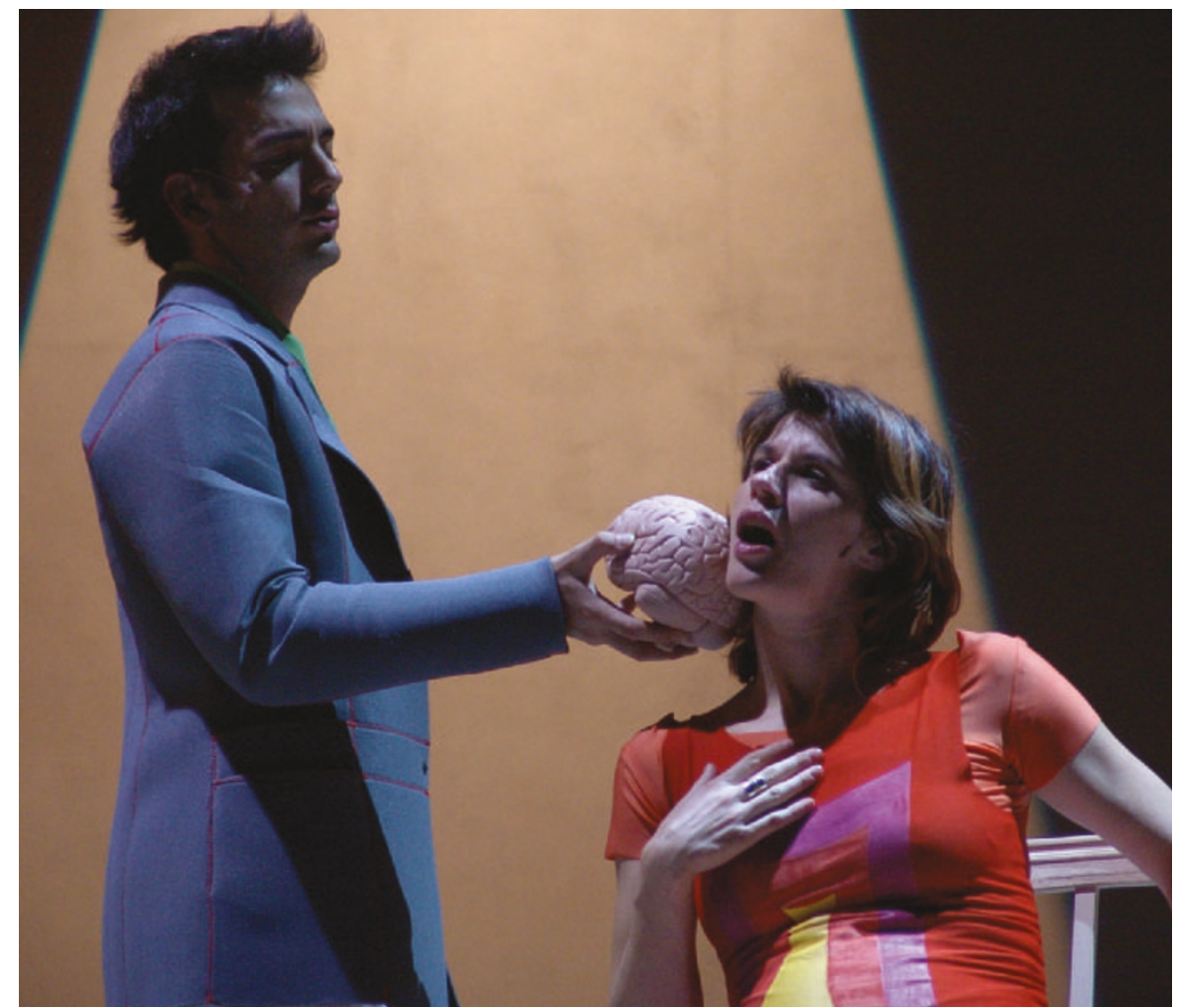

The Darwin Variations, featuring Irene Jacob (right), ponders the future transformation of humanity.

The curtain rises, for instance, on an empty stage. Two actors appear, wearing dark glasses, carrying a bench, a pebble and an egg. Off stage a blind man on his deathbed debates the existence of God with a priest, based on their different experiences of the natural world. The conversation shifts, and the question becomes whether, given a choice, a blind man who knows the world by touch alone would choose to have eyes or a longer pair of arms. Just then, one of the blind men on stage throws up the egg, and the other catches it in mid-air.

In another scene, a woman sitting on a bench, cutting up newspaper, asks the man beside her if contempt is expressed by a slight pouting and a flaring of the nostrils with a small expiration - one of Darwin's observations from his book The Expression of the Emotions in Man and Animals. The man doesn't respond. She asks him, indignantly, if the expression for disgust resembles that of someone about to spit. He gazes off into the distance. Enraged, she threatens him with her scissors. His face contorts, he throws himself at her, and the scene ends in a fight to the death.

The play is funny, original and anything but didactic. It takes familiar ideas and pursues them through their serious implications ad absurdum. The third in a trilogy based on metamorphoses, The Darwin Variations is, in a sense, a product of evolution itself. The actors began with a script and moulded it into a piece of theatre, according to their own continuously evolving ideas. It will probably continue to evolve through its run at the Théâtre National de Chaillot in Paris. Those attending on the last night may see something quite different to those present at the opening - not necessarily any better or worse, just different.

Laura Spinney is a freelance writer based in London and Paris. 